\title{
A necessária integração entre alfabetização e letramento na aprendizagem inicial da língua escrita
}

\author{
Vicente de Souza CARDOSO JR (1) \\ Universidade Federal do Rio Grande do Sul (UFRGS)
}

RESUMO

Na conferência Alfabetização e Letramento - TeoriaS e PráticaS, que integrou a programação do evento Abralin ao Vivo - Linguists Online, a professora Magda Soares apresenta a concepção de alfabetização e letramento que tem orientado o trabalho na Educação Infantil e nos anos iniciais do Ensino Fundamental na bem-sucedida experiência do município de Lagoa Santa (MG). Esta resenha apresenta aspectos fundamentais dessa concepção, que, segundo Soares, é centrada na orientação do processo de aprendizagem da língua escrita pela criança, com atenção a seu desenvolvimento cognitivo e linguístico. A conferencista apresenta algumas das principais teorias psicológicas e linguísticas que oferecem evidências científicas importantes para a alfabetização e o letramento, defendendo que esses processos sejam sempre integrados. Algumas dessas teorias são recuperadas nesta resenha, que também destaca divergências entre a concepção apresentada por Magda Soares e a que é proposta pela atual Política Nacional de Alfabetização do governo federal.

\section{ABSTRACT}

At the lecture Alfabetização e Letramento - TeoriaS e PráticaS, which integrated the program of the online event Abralin ao Vivo - Linguists Online, Professor Magda Soares presents the concept of literacy that has been guiding the strategies used in the Preschool and first grades of Elementary School in Lagoa Santa (MG, Brazil) and has led to the city's successful 


\section{REVISTA DA ABRALIN}

experience. This review presents fundamental aspects of this conception, which, according to Soares, is centered on giving attention to the child's cognitive and linguistic development while guiding their process of learning the written language. The lecturer presents some of the main psychological and linguistic theories that offer important scientific evidence about the initial learning of written language. Soares argues that children must learn the alphabetic writing system whilst assimilating the social uses of reading and writing. Some of these theories are recovered in this review. It also highlights divergences between the conception of literacy presented by Magda Soares and the one currently proposed by the Brazilian federal government.

\section{PALAVRAS-CHAVE}

Alfabetização. Letramento. Desenvolvimento cognitivo e linguístico da criança. Magda Soares.

\section{KEYWORDS}

Initial learning of written language. Literacy. Child's cognitive and linguistic development. Magda Soares.

Refletir sobre o valor das conjunções "e" presentes no título de uma conferência destinada a linguistas e a professores de língua é uma boa maneira de lembrar-nos que o sentido não é construído apenas nos usos ditos espontâneos da língua, mas também em sua análise. Com esse gesto, a professora Magda Soares deu início à sua apresentação intitulada Alfabetização e Letramento - TeoriaS e PráticaS, no dia de encerramento do evento Abralin ao Vivo - Linguists Online, 31 de julho de 2020, após três meses de programação diária.

Quando a conferencista destaca o papel da primeira conjunção aditiva, convoca-nos a compreender "alfabetização" e "letramento" como processos que "andam juntos", ou, ainda, como parte de um mesmo processo - a aprendizagem inicial da língua escrita. Soares também explicita o sentido em que nos convida a pensar a relação entre "teoriaS" e "práticaS": "não é 'teorias aplicadas às práticas', nem 'práticas apoiadas em teorias' - são teorias e práticas somadas, interagindo". Os plurais grafados em maiúscula também serão significativos ao longo da conferência.

Desde o início, Magda Soares ressalta que a concepção de alfabetização e letramento que apresenta é resultado de uma construção coletiva, que decorre justamente das interações entre teorias e práticas. Dois espaços em especial têm possibilitado essas interações no trabalho da pesquisadora: 


\section{REVISTA DA ABRALIN}

- a rede municipal de ensino de Lagoa Santa $(\mathrm{MG})$, onde atua como voluntária há 12 anos, coordenando o Núcleo de Alfabetização e Letramento, que conta com um professor representante de cada escola da rede;

- o Centro de Alfabetização, Leitura e Escrita (Ceale) da Faculdade de Educação da UFMG, fundado em 1990 a partir da pesquisa Alfabetização no Brasil: o estado do conhecimento, lançada por Soares nos anos 1980 e ainda em andamento (coordenada hoje por Francisca Maciel, da FaE/UFMG).

Outro marco do trabalho de Soares é a publicação de Alfabetização: a questão dos métodos (SOARES, 2016), obra vencedora do Prêmio Jabuti em 2017 como Livro do Ano de Não-Ficção, em que a autora se debruça sobre os principais estudos do campo produzidos internacionalmente. Com base em seu trabalho de referência na área, a pesquisadora adverte: "Nós temos feito repetidamente a pergunta: qual é o método melhor? A pergunta não é essa. Essa pergunta é a pergunta errada." E propõe, como a pergunta certa, a seguinte: "como devemos orientar o processo de aprendizagem do sistema de escrita alfabético e de habilidades de seu uso, respeitando as evidências científicas que nos dão as teorias do desenvolvimento cognitivo e linguístico da criança?". Nessa mudança, o foco deixa de ser no ensino, voltando-se para a orientação do processo de aprendizagem da criança.

Ainda para situar a concepção apresentada, é importante mencionar outra a que ela se opõe: "aquilo que nós construímos como uma concepção de alfabetização e letramento diverge fundamentalmente da assumida pelo plano nacional de alfabetização que o governo atual está propondo", afirma Soares. Para compreender essa divergência, duas noções da Política Nacional de Alfabetização - PNA (BRASIL, 2019) devem ser destacadas. Primeiro, a compreensão do sistema alfabético como um código. "Se alguém é alfabetizado, significa que é capaz de decodificar e codificar qualquer palavra em sua língua." (BRASIL, 2019, p. 19). Segundo, a proposta para o ensino desse código, com ênfase na "instrução fônica sistemática" (BRASIL, 2019, p. 16), "de forma explícita e sistemática, numa ordem que deriva do mais simples para o mais complexo" (BRASIL, 2019, p. 18).

A política acima - à qual, lembremos, a conferencista se opõe - recomenda o ensino do princípio alfabético com foco em estratégias de codificação/decodificação, ao passo que Magda Soares defende que se oriente a criança na aprendizagem desse princípio como um sistema de representação. Uma diferença fundamental está em considerar os conceitos de escrita que a criança é capaz de construir em cada momento de seu desenvolvimento cognitivo e linguístico. Nesse sentido, são relevantes as teorias que indicam as fases desse desenvolvimento. Soares destaca estudos de Vygotsky (1935) e Luria (1929), sobre pré-história da escrita; de Read (1970) e Bissex (1980), sobre escritas inventadas; de Gentry (1982), sobre estágios de desenvolvimento; de Frith (1985) e Ehri (1997), sobre fases de desenvolvimento da leitura; e, por fim, de Ferreiro e Teberosky (1986), sobre a psicogênese da língua escrita.

Entre esses estudos, o último é o de maior influência no campo da alfabetização no Brasil. Como Soares observa, sua relevância tem relação com o fato de que "põe o foco na criança, e não 


\section{REVISTA DA ABRALIN}

propriamente no sistema - é a criança na interação com o sistema alfabético". Na conferência, Soares explicou como as fases de conceitualização da escrita descritas pela teoria psicogenética (garatuja; escrita com letras; silábica sem valor sonoro; silábica com valor sonoro; silábico-alfabética; alfabética; e ortográfica) têm sido articuladas às práticas de alfabetização e letramento na rede de ensino de Lagoa Santa.

E por que é possível considerar as fases da teoria psicogenética como uma evidência científica relevante para a alfabetização em língua portuguesa? Para Soares, pelo fato de a pesquisa ter sido "replicada e comprovada em línguas de ortografias transparentes, ou próximas da transparência", como o espanhol (idioma original da pesquisa), o catalão, o italiano e o português, tanto o brasileiro como o europeu. Em línguas de ortografia transparente, as sílabas são bem demarcadas e há consistência na correspondência entre fonemas e grafemas - em contraposição, quanto maior a opacidade da ortografia de uma língua, menos essas características serão observadas. Aqui, outra diferença em relação à proposta do governo federal é marcada: a PNA é fortemente baseada em um estudo (NATIONAL READING PANEL, 2000) sobre alfabetização em língua inglesa, cuja ortografia "é sempre indicada como uma das mais opacas", afirma Soares. Além disso, a conferencista também considera o estudo desatualizado, mesmo nos EUA, onde foi realizado, e também parcial - "o Reading Panel chegou à conclusão que o melhor era o método fônico, embora outros métodos não tenham sido estudados".

Outro ponto da divergência fundamental entre as duas concepções: a PNA postula a pronúncia de fonemas como prática essencial do processo de alfabetização, o que, segundo Soares, contraria teorias linguísticas: "é uma evidência científica da Fonologia que os fonemas não são pronunciáveis. Eles expressam uma relação linguística abstrata. Não é possível pronunciar um fonema, a não ser as vogais ('a', 'e', 'i', 'o', 'u'), assim mesmo, com diferenças entre /a/, /ã/ etc.". Neste ponto, a conferencista faz uma interessante comparação: essencialmente, a criança identifica fonemas da mesma forma como são feitas as descrições fonológicas das línguas. Em resumo, tanto para a criança quanto para o linguista, "dois sons são identificados como dois fonemas quando estão em contraste e oposição em palavras com significados diferentes". Por exemplo, 'bata' e 'mata', "duas palavras que se distinguem oralmente apenas por sons situados na mesma posição na cadeia sonora". Segundo Soares, a partir do momento em que a conceitualização de escrita da criança corresponde à fase "silábica sem valor sonoro", o professor de alfabetização irá fundamentalmente "trabalhar com contrastes e oposições, para que a criança chegue à consciência grafofonêmica, e aí possa aprender sistematicamente, como quer o método fônico, e explicitamente o conhecimento das relações fonema-grafema".

Esperar o desenvolvimento da consciência grafofonêmica para depois investir no processo de letramento é um erro grave, afirma a conferencista. Segundo Soares, as teorias da Linguística Textual, do Discurso e dos Gêneros, assim como as práticas vivenciadas em Lagoa Santa, oferecem evidências de que o desenvolvimento cognitivo e linguístico da criança permite e favorece o trabalho com textos reais desde a Educação Infantil, o que está contemplado nas metas da rede. Como exemplo, apresenta o quadro das "habilidades de leitura e interpretação no ciclo de alfabetização e letramento", que, na pré-escola, incluem "relacionar texto e ilustrações" e "incorporar ao vocabulário novas palavras encontradas em textos", entre outras. É importante mencionar que as metas do 


\section{REVISTA DA ABRALIN}

município - tanto de alfabetização quanto de letramento - são construídas a partir das habilidades que se verifica que as crianças daquela mesma etapa educacional desenvolveram em anos anteriores. Com isso, a conferencista enfatiza que a concepção de alfabetização e letramento que apresenta, além de construída coletivamente, é aberta à atualização.

Somada às reflexões sobre teorias e práticas, uma importante lição da conferência de Magda Soares vem do uso da língua. A pesquisadora é uma das principais responsáveis pela introdução do termo "letramento" no Brasil. Sua obra é marcada pela reiterada afirmação da necessidade de integrar a alfabetização e o letramento. Após décadas contribuindo para que os dois termos tenham cada um seu espaço na língua, o trabalho mais recente de Magda Soares nos convida a explorá-los também de outro modo. E até nos instiga a pensar nos limites do sentido de uma adição pela sintaxe: afinal, em "alfabetização e letramento", continua havendo palavras distintas, portanto, uma separação linguística dos conceitos. É aí que desponta a intimidade com o objeto de quem se dedica com tanto rigor e entusiasmo a estudá-lo. "Quando as pessoas perguntam: qual é o método que vocês usam em Lagoa Santa? Nós não usamos um método! Se quiser que chame um método, nós alfaletramos, nós usamos o alfaletrar, que é alfabetizar e letrar ao mesmo tempo."

\section{REFERÊNCIAS}

ALFABETIZAÇÃO e Letramento - TeoriaS e PráticaS. Conferência apresentada por Magda Soares [s.l., s.n.], 2020, 1 vídeo (2h 26 min 15s). Publicado pelo canal da Associação Brasileira de Linguística. Disponível em: https://www.youtube.com/watch?v=UnkEuHpxJPs. Acesso em: 03 ago. 2020.

BISSEX, G. L. Gnys at wrk: a child learns to write and read. Cambridge: Harvard University Press, 1980. 223p.

BRASIL. Ministério da Educação. Secretaria de Alfabetização. PNA: Política Nacional de Alfabetização. Brasília: MEC, Sealf, 2019. 54p. Disponível em: http://portal.mec.gov.br/images/banners/caderno_pna_final.pdf. Acesso em: 03 ago. 2020.

EHRI, L. Learning to read and learning to spell are one and the same, almost. In: PERFETTI, C.; RIEBEN, L.; FAYOL, M. (org.). Learning to spell: Research, theory, and practice across languages. Mahwah: Erlbaum, 1997. p. 237-269.

FERREIRO, E.; TEBEROSKY, A. Psicogênese da língua escrita. Tradução: Diana Myriam Lichtenstein et al. Porto Alegre: Artes Médicas, 1986. 284p.

FRITH, Uta. Beneath the surface of developmental dyslexia. In: PATTERSON, K. E.; MARSHALL, J. C.; COLTHEART, M. (eds.). Surface dyslexia: neuropsychological and cognitive analyses of phonological reading. London: Lawrence Erlbaum, 1985. p. 301-330.

LURIA, A. R. O desenvolvimento da escrita na criança. In: VYGOTSKY, L. S.; LURIA, A. R.; LEONTIEV, A. N. Linguagem, Desenvolvimento e Aprendizagem. Tradução: Maria da Penha Villalobos. São Paulo: Ícone: Editora da Universidade de São Paulo, 1998. p. 103117. Original de 1929.

NATIONAL READING PANEL. Teaching children to read: an evidence-based assessment of the scientific research literature on reading and its implications for reading instruction. Washington: National Institute of Child Health and Human Development, 2000. Disponível em: https://www.nichd.nih.gov/sites/default/files/publications/pubs/nrp/Documents/report.pdf. Acesso em: 12 ago. 2020. 


\section{REVISTA DA ABRALIN}

READ, W. C. Children's perceptions of the sounds of English: phonology from three to six. 1970. $464 \mathrm{f}$. Tese de Doutorado. Harvard Graduate School of Education, Harvard University, Cambridge, 1970.

SOARES, M. Alfabetização: a questão dos métodos. São Paulo: Contexto, 2016. 384p.

VYGOTSKY, L. S. A pré-história da língua escrita. In: VYGOTSKY, L. S. A formação social da mente. Tradução: José Cipolla Neto et al. São Paulo: Martins Fontes, 1984. p. 119-134. Original de 1935, publicação póstuma. 